\title{
Pharmacotherapy of Co-Occurring Schizophrenia and Substance Use Disorders
}

\author{
Sarah C. Akerman • Mary F. Brunette • \\ Douglas L. Noordsy • Alan I. Green
}

Published online: 27 September 2014

(C) Springer International Publishing AG 2014

\begin{abstract}
Substance use disorders, common in patients with schizophrenia, can lead to poor outcomes. Here we review the literature on the use of antipsychotics in patients with cooccurring schizophrenia and substance use disorder as well as evidence for the use of adjunctive pharmacological treatments targeting substance use in these patients. We also discuss a neurobiological formulation suggesting that the cooccurrence of these disorders may be related to a dysfunction in the dopamine mediated brain reward circuitry. Typical antipsychotics do not appear to decrease substance use in this population. Randomized, controlled trials provide some support for use of the atypical antipsychotic clozapine for cooccurring cannabis use disorder, naltrexone and disulfiram for alcohol use disorder, and also nicotine replacement therapy, sustained-release bupropion and varenicline for tobacco use disorder. Nonetheless, data regarding treatment in patients with these co-occurring disorders are still limited, and many studies reported to date have been either underpowered or did not include a control condition. Further research is needed to evaluate optimal pharmacotherapeutic strategies for this population.
\end{abstract}

Keywords Schizophrenia $\cdot$ Substance use disorder . Antipsychotic $\cdot$ Brain reward $\cdot$ Clozapine

\section{Introduction}

Schizophrenia, characterized by hallucinations, delusions, and disorganized behavior and thinking, occurs in $1 \%$ of the population. Nearly $50 \%$ of people with schizophrenia have a lifetime substance use disorder [1], a rate three to four times

S. C. Akerman • M. F. Brunette • D. L. Noordsy • A. I. Green $(\bowtie)$ Department of Psychiatry, Geisel School of Medicine at Dartmouth, Lebanon, NH 03756, USA

e-mail: alan.i.green@dartmouth.edu higher than the general population [2]. Patients with schizophrenia and co-occurring substance use disorders (i.e., "dual diagnosis" patients) have more severe psychiatric symptoms [3], are less treatment compliant [4], and have increased rates of hospitalization [5] compared to those with schizophrenia alone. Moreover, patients with schizophrenia die approximately 25 years prematurely, often due to heart disease, cancer, cerebrovascular disease, and lung disease, which can all be caused or exacerbated by substance use $[6 \bullet, 7]$.

Several theories attempt to explain the high co-occurrence of schizophrenia and substance use disorders. In the neural stress diathesis model, neurobiological vulnerability interacts with environmental stressors, including substance use, to lead to substance use disorder in vulnerable individuals $[8,9]$. In support of this model, substance use has been associated with a greater likelihood of the development of schizophrenia [10], and the "high output" variant of the catechol-o-methyl transferase (COMT) gene in adolescent cannabis users has been associated with the onset of psychotic symptoms in adulthood $[11 \bullet]$. Moreover, those with schizophrenia appear to be more vulnerable to the detrimental effects of substance use [12].

The self-medication hypothesis [13] proposes that individuals with schizophrenia use substances to ameliorate symptoms of schizophrenia or side effects of medications used to treat schizophrenia [14]. Although individuals with schizophrenia subjectively report improvements in sleep, mood, and other symptoms with substance use, substance use does not always correlate with symptom severity and studies have been unable to confirm the self-medication hypothesis as the cause of elevated rates of substance use in this population $[15,16]$.

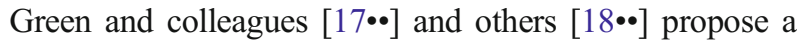
third model. This reward circuitry dysfunction model postulates that a dysregulation in the dopamine-mediated mesocorticolimbic brain reward pathway underlies the cooccurrence of schizophrenia and substance use disorders, and that substance use may temporarily ameliorate this 
deficit, though substance use also worsens symptoms and the course of schizophrenia [19].

Optimal treatment for co-occurring schizophrenia and substance use disorder involves coordinated psychotherapy, psychosocial interventions, and pharmacotherapy [20]. Although motivational enhancement, cognitive behavioral therapy, group counseling, contingency management, supported employment, assertive community treatment, and long term residential treatment can improve outcomes in dual diagnosis patients treated with antipsychotics, many patients do not respond and relapse rates are high [21,22]. Thus, there is clearly a need for better treatments. In this review we discuss evidence supporting the pharmacologic management of substance use in patients with co-occurring schizophrenia and substance use disorders and we discuss future directions toward the development of improved pharmacotherapies. Since antipsychotics are the first line of treatment for people with schizophrenia, we first review their use in this population. Then we discuss other pharmacotherapeutic strategies and also touch upon the possible use of neurostimulating treatments.

\section{Antipsychotics}

\section{Typical Antipsychotics}

Typical antipsychotics, which share a common mechanism of potent antagonism of the dopamine D2 receptor, appear to be less effective in those with co-occurring psychotic and substance use disorders than in those with psychosis alone [23]. In most (but not all, [24]) studies, these agents do not decrease and may actually increase substance use and craving [25-27]. Green and others suggested that the potency of the dopamine D2 receptor blockade produced by typical antipsychotics, while responsible for antipsychotic effects, might inhibit the ability of these medications to limit substance use $[17 \bullet \bullet, 28]$.

\section{Atypical Antipsychotics}

Atypical or "second generation" antipsychotics share a common mechanism of a weaker dopamine D2 blockade and/or a broader base of pharmacological action than typical antipsychotics, which may be of particular significance in the treatment of patients with co-occurring substance use disorders $[17 \bullet \bullet]$. Here we review data on clozapine, risperidone, olanzapine, quetiapine and aripiprazole. We are not aware of data published on the impact of the other atypical antipsychotics on substance use disorders in patients with schizophrenia.

\section{Clozapine}

The atypical antipsychotic clozapine can effectively reduce psychotic symptoms in patients with schizophrenia, but its use has been limited to patients who are refractory to other pharmacotherapies because of its side effect profile. This includes weight gain, sedation, seizures, and the risk of agranulocytosis, which requires regular blood count monitoring [29]. Unlike the typical agents, however, there is some evidence that clozapine may decrease substance use in patients with schizophrenia.

Two small chart reviews showed possible benefits of clozapine for decreasing substance use [30, 31]. In 151 prospectively followed patients with schizophrenia or schizoaffective disorder and substance use disorder, a higher proportion of patients receiving clozapine versus those taking another atypical antipsychotic achieved remission from a drug (64 \% vs. $30 \%$ ) or alcohol use disorder (79\% vs. $34 \%$ ) [32•]. Following the same group over the next year showed that those in remission and treated with clozapine had lower rates of relapse to substance use ( $8 \%$ ) than those treated with other antipsychotics (40\%) [33]. Another open prospective study showed a reduction in cigarette smoking as demonstrated by lower expired carbon monoxide (effect size $\sim 0.8$ ) among those taking clozapine compared to those treated with typical antipsychotics [34].

Two small randomized, controlled trials have been completed. In the first, 31 subjects with schizophrenia and cannabis use disorder were randomized to clozapine or continued on their current antipsychotic for twelve weeks [35]. The clozapine group used less cannabis than the other group (effect size $\sim 0.6$ ). In the second trial including 28 patients with schizophrenia and cannabis use disorder, those randomized to clozapine demonstrated a larger decrease in subjective cannabis craving and a larger decrease in bilateral insula activation during a cannabis word Stroop task compared to those randomized to risperidone [36•].

While the basis of clozapine's apparent ability to decrease substance use is not known, Green and colleagues hypothesized that it could be due to clozapine's broad spectrum pharmacological effects, including its weak blockade of the dopamine D2 receptor, potent blockade of the norepinepherine alpha-2 receptor, and its ability to increase norepinepherine levels in the brain and plasma. They further suggested that these combined effects of clozapine may ameliorate a deficiency in the mesocorticolimbic reward circuitry postulated to occur in people with schizophrenia [17••, 19]- consistent with the findings by Machielsen and colleagues [36 ${ }^{\circ}$.

\section{Risperidone}

Given the beneficial effects of clozapine, a number of studies assessed whether other antipsychotics share clozapine's 
ability to decrease substance use in patients with schizophrenia. This is of particular importance because clozapine tends to be used infrequently, given its side effects. While some suggested that the atypical antipsychotic risperidone might reduce craving and relapse more than haloperidol in patients with schizophrenia and cocaine use disorder (e.g. [37]), subsequent studies comparing risperidone to other atypical agents have been less promising. Risperidone appears less able to limit alcohol and cannabis use [31] and craving [36•,38] than clozapine, and it demonstrates no benefit compared to olanzapine in reducing cannabis use in patients with schizophrenia $[39,40]$.

In patients with tobacco use disorder, however, those treated with group therapy and nicotine replacement therapy and also taking atypical antipsychotics, including risperidone $(\mathrm{N}=$ 18), had a $55.6 \%$ smoking cessation rate (vs. $22.2 \%$ in those taking typical antipsychotics $(\mathrm{N}=27)$ ). Patients on risperdone and olanzapine had the highest quit rates [41•].

Given poor adherence to oral medications common in patients with schizophrenia [42], studies have assessed longacting, injectable risperidone. Results in patients with cooccurring disorders conflict. In an open six month trial of 115 patients with schizophrenia and substance use disorder, those treated with long acting injectable risperidone had fewer positive urine drug screens compared to those treated with the long acting injectable typical antipsychotic, zuclopenthixol, although the difference was small [43]. Green and colleagues randomized 95 patients to treatment with either oral risperidone or long acting injectable risperidone to treat alcohol use disorder in patients with schizophrenia. The study suggested that, while patients in both groups continued drinking, those treated with injectable risperidone used less alcohol than those treated with oral risperidone [44•]. Moreover, a post-hoc analysis of alcohol use in a different one-year study comparing long-acting injectable risperidone to oral antipsychotic treatment in patients with unstable schizophrenia showed that scores on the alcohol composite index of the Addiction Severity Index favored people assigned to long-acting injectable risperidone [45]. However, Leatherman and colleagues, who randomized 396 patients with schizophrenia or schizoaffective disorder to long acting risperidone or an oral atypical antipsychotic, found no difference in substance use outcomes between the groups [46].

\section{Olanzapine}

Data regarding efficacy of olanzapine in patients with cooccurring schizophrenia and substance use disorders are similarly mixed. In one small observational study, substance abuse declined with olanzapine [47]. Other naturalistic studies, however, did not find improvements in substance use among patients switched to olanzapine compared to those maintained on typical antipsychotics [48, 49]. In a longitudinal, naturalistic cohort study of 123 patients with cannabis use disorder and a psychotic disorder [38], olanzapine treatment led to less cannabis craving compared to risperidone but did not differ from clozapine in its effect on cannabis craving [38].

Two rigorous trials comparing olanzapine to haloperidol in patients with schizophrenia found conflicting results for cocaine craving along with no significant change in cocaine positive urine drug screens $[50,51]$. Two randomized trials showed that olanzapine did not convey an advantage over risperidone in reducing cannabis use among schizophrenia patients $[39,40]$. However, the study of nicotine replacement therapy mentioned above reported higher rates of smoking cessation among patients on risperdone and olanzapine compared to those on typical antipsychotics [41•].

\section{Quetiapine}

Although initial research on effects of quetiapine on alcohol drinking in the general population was promising, a recent randomized controlled trial showed that this medication did not improve drinking outcomes more than placebo in patients with alcohol dependence [52]. While two small, open label studies of quetiapine for patients with schizophrenia and substance use disorder found improvements in severity of substance use [53] and mean days of drinking per week [54], no randomized, controlled trials of quetiapine have been completed in this population.

\section{Aripiprazole}

The data on aripiprazole are also limited. Two small, open label trials showed reductions in cocaine and alcohol craving $[55,56]$; one also showed reduction in dollars spent on alcohol but not a reduction in cocaine use [56], and the other showed a reduction in cocaine positive urine tests [55]. In an open label trial of 139 patients with schizophrenia and tobacco use disorder randomly assigned to haloperidol, risperidone, olanzapine, or aripiprazole, subjects on aripiprazole $(\mathrm{N}=31)$ showed a decrease in tobacco craving and nicotine dependence [57].

\section{Summary of Data on Antipsychotics}

While typical and atypical antipsychotics effectively reduce psychotic symptoms in patients with schizophrenia, research has not demonstrated an optimal antipsychotic treatment for patients with co-occurring schizophrenia and substance use disorders. Typical antipsychotics do not appear to decrease substance use, although preliminary studies suggest clozapine may be effective in treating these dual diagnosis patients. Further research is needed to clarify clozapine's optimal use in this population. Research on risperidone, olanzapine, 
quetiapine, and aripiprazole thus far has been less promising and, to our knowledge, no data have been published on the possible role of the other, newer atypical antipsychotics in such patients.

\section{Adjunctive Treatments}

There are a number of pharmacologic agents available for use in treating substance use disorders that have been used as adjunctive agents to antipsychotics in patients with schizophrenia and co-occurring substance use disorders. The Food and Drug Administration has approved three drugs for the treatment of alcohol use disorder - disulfiram (Antabuse), naltrexone (ReVia, Vivitrol), and acamprosate (Campral); three drugs for the treatment of opioid use disorder - methadone (Dolophine), buprenorphine (Suboxone, Subutex), and naltrexone; and three drugs for the treatment of tobacco use disorder - nicotine (e.g. Nicorette), bupropion (Zyban), and varenicline (Chantix). Other agents used in the treatment of substance use disorders including anticonvulsants, tricyclic antidepressants, cannabinoids, and neurostimulation treatments are also discussed here.

\section{Disulfiram}

Disulfiram inhibits the enzyme aldehyde dehydrogenase to prevent the breakdown of acetaldehyde to acetate. After consuming alcohol while taking this medication, acetaldehyde accumulates in the body, causing patients to experience symptoms such as flushing, changes in blood pressure, sweating, headache, palpitations, nausea and vomiting. Multiple studies have shown that short-term, supervised use of disulfiram among motivated patients deters alcohol use [58].

Despite early reports that disulfiram may exacerbate psychiatric symptoms, a retrospective chart review suggested that disulfiram can be a safe and effective adjunctive treatment in patients with schizophrenia and alcohol use disorder [59]. In a randomized trial comparing disulfiram, naltrexone, and the combination of disulfiram and naltrexone to placebo, patients with psychotic illness and alcohol use disorder $(\mathrm{N}=66)$ treated with disulfiram had more days of abstinence and fewer heavy drinking days, with no change in psychotic symptoms compared to placebo [60•].

\section{Naltrexone}

Naltrexone, a competitive antagonist at $\mu$-opioid receptors, decreases the pleasant and euphoric effects of drinking [61] through indirect action on the dopamine mediated pathway from the ventral tegmental area to the nucleus accumbens, the primary pathway involved in reinforcement, motivation, and reward anticipation [62]. Naltrexone reduces heavy drinking and the number of drinking days in alcohol dependent patients in the general population but does not significantly enhance abstinence [63].

For patients with schizophrenia, an early, small, open label trial was promising [64]. Following this, the trial in psychotic patients noted above (a randomized trial comparing disulfiram, naltrexone, and the combination of disulfiram and naltrexone to placebo) found that patients treated with naltrexone had more days of abstinence and fewer heavy drinking days as compared to those treated with placebo, with no change in psychotic symptoms [60•]. The same research group also demonstrated the efficacy of naltrexone in this population with apparent safety in a small, placebo controlled double blind study of naltrexone and cognitive behavioral therapy in 31 patients with schizophrenia and alcohol use disorder [65]. Patients treated with naltrexone had significantly fewer drinking days, fewer heavy drinking days, and reported less craving than did those treated with placebo, with no worsening psychosis. A long-acting, injectable form of naltrexone is available [66], but to our knowledge it has not been studied in patients with schizophrenia and alcohol disorders.

\section{Acamprosate}

Acamprosate is thought to restore the balance between inhibitory and excitatory systems [67] involved in the negative reinforcing effects of alcohol and the response to alcohol cues [68]. It may also reduce the rewarding effects of alcohol [69]. Studies in those with alcohol use disorder found that acamprosate reduces the risk of relapse after detoxification from alcohol and increases cumulative abstinence time [70].

Only one small, randomized trial $(\mathrm{N}=23)$ of the effect of acamprosate on alcohol drinking patients with schizophrenia and co-occurring alcohol use disorder has been reported, showing that acamprosate was not more effective than placebo in reducing drinking among these patients [71]. There was also no effect on psychotic symptoms or cognitive function [72].

\section{Anticonvulsants}

Some anticonvulsants have shown promise in the treatment of alcohol dependence, but none are currently FDA approved for this use. Topiramate, believed to antagonize glutamate receptors and facilitate $\mathrm{GABA}_{\mathrm{A}}$-mediated currents [73], appears to reduce heavy drinking in alcohol dependent patients but is often not well tolerated [74]. Valproate, an anticonvulsant and mood stabilizer, may increase time to relapse to heavy drinking in abstinent alcohol dependent patients [75] and reduce heavy drinking in patients with bipolar disorder [76]. Lastly, in a recent study, the anticonvulsant levitiracetam was reported ineffective for the treatment of alcohol dependence in a 
multisite trial [77]. To our knowledge, none of these medications has been studied in people with schizophrenia and substance use disorders.

\section{Tricyclic Antidepressants}

Two small studies published more than 20 years ago demonstrated that tricyclic antidepressants may have a role as an adjunctive treatment (added to typical antipsychotics) in individuals with schizophrenia and substance use disorders [78, 79]. Interestingly, recent animal research in alcohol drinking hamsters (used to model some aspects of alcohol drinking in people with schizophrenia) by our group suggests that the combination of the tricyclic antidepressant desipramine with the antipsychotic risperidone can reduce alcohol drinking more than either drug alone [80]. Feasibility trials are underway to assess the value of this combination in patients with schizophrenia and alcohol use disorder.

\section{Opioid Substitution Therapy}

To our knowledge there are no published trials of methadone or buprenorphine for the treatment of patients with schizophrenia and co-occurring opioid use disorder. There have been, however, brief reports suggesting that these medications may be helpful in this population [81, 82].

\section{Cannabinoids}

The endocannabinoid system modulates dopamine transmission leading to the notion that targeting cannabinoid receptor activity may be beneficial for the treatment of substance use disorders. Despite encouraging data from animal studies, a placebo-controlled double blind study of the cannabinoid inverse agonist rimonabant in alcohol dependent patients (without a co-occurring psychiatric disorder) demonstrated that it did not prevent relapse to alcohol use [83]. Recently however, Fischer and colleagues (2014) reported on a preliminary imaging study suggesting that smoked cannabis or oral tetrahydrocannabinol, the primary psychoactive agent in cannabis, partially corrects a brain reward system deficit in patients with schizophrenia and cooccurring cannabis use disorder [84]. These data, if confirmed by future research, may suggest that a low dose of a cannabinoid agonist, given with an antipsychotic, could be tested in an attempt to decrease cannabis use in patients with schizophrenia.

\section{Nicotine Replacement Therapy}

In two open studies of nicotine replacement therapy for tobacco use disorder, nicotine patch, gum or both given with weekly group counseling led to abstinence in $12-13 \%$ of smokers with schizophrenia over a six month follow-up period $[85,86]$. Another longitudinal study in 68 smokers with schizophrenia assigned to 8 weeks of nicotine patch found that $23.1 \%$ achieved continuous abstinence at 3 month follow up compared to $0 \%$ in the control group [87]. Lastly, in a randomized, controlled trial of nicotine replacement with eight weeks of psychotherapy, compared to treatment as usual in patients with a psychotic disorder, rates of abstinence did not significantly differ between groups; however, the treatment group had a greater reduction in smoking at 3 months (43.5\% reduced cigarette consumption by at least $50 \%$, compared to $16.6 \%$ of the comparison group) [88].

Novel strategies to treat tobacco use disorder in patients with schizophrenia are being explored. In a small, controlled study, Tidey and colleagues demonstrated the potential benefits of very low nicotine content cigarettes [89]. Moreover, one early observational study of electronic-cigarettes (not approved by the Food and Drug Administration as a cessation strategy) showed that $50 \%$ of smokers with schizophrenia had a $50 \%$ reduction in smoking and $14.3 \%$ achieved abstinence at 1 year [90]. Over the coming years, we can anticipate more innovative uses of nicotine to decrease tobacco smoking.

\section{Varenicline}

Varenicline, a partial nicotinic receptor agonist [91], may affect dopamine release in the ventral tegmental area and striatum of the mesocorticolimbic reward pathway in response to nicotine [92]. Although a number of studies have demonstrated a role for this medication as an aid in smoking cessation, varenicline carries a Food and Drug Administration black box warning due to reports of depression and suicidal ideation associated with its use, often deterring providers from using varenicline in patients with co-occurring psychiatric disorders. However, a number of studies over the past few years demonstrated that varenicline appears to safely reduce smoking in patients with schizophrenia. A small trial using varenicline as an adjunctive treatment with healthy lifestyle intervention was promising [93] and was followed by two studies of smokers with schizophrenia treated with varenicline and cognitive behavioral therapy for twelve weeks. In one study, $47.3 \%$ achieved at least two consecutive weeks of continuous abstinence at week 12 [94] and in the second, $60.4 \%$ met criteria for two week point prevalence abstinence at week twelve [95].

Two randomized double-blind studies provided further evidence for its use in this population. The first, a 12-week trial, found that varenicline treatment was associated with a $19 \%$ smoking cessation rate as compared to $4.7 \%$ for placebo at 12 weeks [96]. The rate of adverse events was similar between the groups, with no significant change in psychotic or other mood symptoms. The second, a relapse prevention study in patients with severe mental illness (91\% with schizophrenia spectrum disorders) reported that after a year, point prevalence 
abstinence rates in those maintained on varenicline were higher than in those treated with placebo after an initial response to varenicline (60\% vs. $19 \%$ ) [97••]. There was a similar rate of adverse events in both groups without a change in psychotic or other mood symptoms between groups. A possible benefit of varenicline is that it may attenuate nicotine withdrawal-related cognitive dysfunction $[98,99]$ and improve performance on cognitive measures [100-102] in smokers with schizophrenia.

Varenicline is also being explored as a treatment for other substance use disorders. A recent, multi-site, randomized, controlled trial showed that varenicline reduced heavy drinking more than placebo in people with alcohol use disorders [103]. However, there has been limited study of varenicline for alcohol use disorder in schizophrenia. The one reported randomized, placebo controlled pilot trial, recruiting only 10 patients, suggested some promise. Although its tolerability was lower than reported in studies of its use for treating tobacco use disorder in patients with schizophrenia, the number of drinks was numerically lower in the group receiving varenicline [104] suggesting that future studies are warranted.

\section{Bupropion}

The antidepressant bupropion has been shown to decrease smoking in patients with schizophrenia. A small, 12 week, placebo controlled trial $(\mathrm{N}=19)$ suggested that bupropion plus cognitive behavioral therapy facilitated smoking cessation (11\% vs. $0 \%$ ) or reduction (66\% vs. $11 \%$ ) [105] with the majority of those who achieved at least a $50 \%$ reduction able to maintain this reduction at two years [106]. Two larger placebo controlled trials showed that bupropion in combination with psychotherapy $(\mathrm{N}=53$ and $\mathrm{N}=32)$ improved abstinence compared to placebo and psychotherapy (16$50 \%$ on bupropion vs. $0-12.5 \%$ on placebo), but these effects did not persist after treatment with bupropion ended [107, 108]. However, prolonged use of bupropion (12 months) may help to sustain smoking abstinence [109]. Moreover, there is evidence that combining bupropion with nicotine replacement therapy [110 $]$ may improve outcomes.

\section{Neurostimulation Therapies}

There is recent interest in the use of transcranial magnetic stimulation (TMS) in the treatment of substance use disorders. Preliminary research suggests that stimulation over the dorsolateral prefrontal cortex can reduce cravings for substances, including alcohol and cigarettes, in people without schizophrenia [111, 112]. One small, randomized study in male patients with schizophrenia and co-occurring tobacco use disorder $(\mathrm{N}=35)$ with TMS showed a reduction of tobacco use during the treatment period among those receiving the active compared to the sham treatment [113]. Lastly, while case reports regarding the potential use of deep brain stimulation for severe substance use disorders have been appearing, (for review, see [114]), randomized trials in patients with or without schizophrenia have not been completed.

\section{Summary and Recommendations}

Substance use disorders commonly co-occur and contribute to a greater overall risk of morbidity and mortality in individuals with schizophrenia. Thus, optimal treatment for patients with schizophrenia must address and treat these co-occurring disorders. While the etiology of substance use in this population is not well understood, it may involve a dysfunction in the dopamine-mediated mesocorticolimbic brain reward pathway. Although preliminary data about the use of the atypical antipsychotic clozapine appears to be promising for the treatment of co-occurring schizophrenia and substance use disorder, no fully powered, randomized trials of clozapine in this population have been published, thus cautious use of clozapine in dual diagnosis patients is appropriate. Randomized trials suggest the potential value of the adjunctive agents naltrexone and disulfiram for co-occurring schizophrenia and alcohol use disorder as well as bupropion and varenicline for co-occurring tobacco use disorder. Given the clinical significance of cooccurring substance use disorder in patients with schizophrenia, further research is needed before the field has a full list of effective pharmacologic treatment approaches for this population.

Acknowledgments This work was supported in part by National Institutes of Health (NIH) grants DA032533, DA034699 and UL1TR001086 (to AIG), and CA168778 (to MFB). The authors thank Karen Odato and Heather Blunt for their assistance with the literature search and Jibran Khokhar for his comments on the manuscript.

\section{Compliance with Ethics Guidelines}

Conflict of Interest Sarah Akerman has received research grant support, unrelated to this article, from the Dartmouth Clinical and Translational Science Institute, under funding from the National Center for Advancing Translational Science of the NIH (\#UL1TR001086). Mary Brunette has received research grant support from the National Cancer Institute, unrelated to this article. Douglas Noordsy has received a consultancy fee from Ostuka, grants from NIDA, NIAAA and Alkermes and royalties from Guildord Press, all unrelated to this article. Alan Green has received research grants from NIH, and from Janssen, Astra Zeneca and Novartis, has served on a Data Monitoring Board for Eli Lilly, and has been an unpaid consultant to Otsuka and Alkermes. He also has 2 pending patent applications regarding the treatment of substance abuse.

Human and Animal Rights and Informed Consent This article does not contain any studies with human or animal subjects performed by the author. 


\section{References}

Papers of particular interest, published recently, have been highlighted as:

- Of importance

-. Of major importance

1. Regier DA, Farmer ME, Rae DS, et al. Comorbidity of mental disorders with alcohol and other drug abuse. Results from the Epidemiologic Catchment Area (ECA) Study. JAMA. 1990;264(19):2511-8.

2. Hartz SM, Pato CN, Medeiros H, et al. Comorbidity of Severe Psychotic Disorders With Measures of Substance Use. JAMA Psychiatry. 2014;71(3):248-54.

3. Swartz MS, Wagner HR, Swanson JW, et al. Substance use in persons with schizophrenia: baseline prevalence and correlates from the NIMH CATIE study. J Nerv Ment Dis. 2006;194(3):164-72.

4. Owen RR, Fischer EP, Booth BM, et al. Medication noncompliance and substance abuse among patients with schizophrenia. Psychiatr Serv. 1996;47(8):853-8.

5. Gupta S, Hendricks S, Kenkel AM, et al. Relapse in schizophrenia: is there a relationship to substance abuse? Schizophr Res. 1996;20(1-2):153-6.

6. Crump C, Winkleby MA, Sundquist K, et al. Comorbidities and mortality in persons with schizophrenia: A Swedish national cohort study. Am J Psychiatry. 2013;170(3):324-33. A large cohort study demonstrating the premature morbidity and mortality in patients with schizophrenia.

7. Colton CW, Manderscheid RW. Congruencies in increased mortality rates, years of potential life lost, and causes of death among public mental health clients in eight states. Prev Chronic Dis. 2006;3(2):A42

8. Fowles D. Schizophrenia: Diathesis-stress revisited. Annu Rev Psychol. 1992;43(1):303-36.

9. Walker EF, Diforio D. Schizophrenia: a neural diathesis-stress model. Psychol Rev. 1997;104(4):667.

10. Degenhardt L, Hall W, Lynskey M. Testing hypotheses about the relationship between cannabis use and psychosis. Drug Alcohol Depend. 2003;71(1):37-48.

11. Caspi A, Moffitt TE, Cannon M, et al. Moderation of the effect of adolescent-onset cannabis use on adult psychosis by a functional polymorphism in the catechol-O-methyltransferase gene: longitudinal evidence of a gene $\mathrm{X}$ environment interaction. Biol Psychiatry. 2005;57(10):1117-27. A key study of the interaction between genetics and environment as it relates to the development of psychosis in adolescent cannabis users.

12. D'Souza DC, Abi-Saab WM, Madonick S, et al. Delta-9tetrahydrocannabinol effects in schizophrenia: implications for cognition, psychosis, and addiction. Biol Psychiatry. 2005;57(6): 594-608.

13. Khantzian EJ. The self-medication hypothesis of substance use disorders: a reconsideration and recent applications. Harv Rev Psychiatry. 1997;4(5):231-44.

14. Siris SG. Pharmacological treatment of substance-abusing schizophrenic patients. Schizophr Bull. 1990;16(1):111-22.

15. Brunette MF, Mueser KT, Xie H, et al. Relationships between symptoms of schizophrenia and substance abuse. J Nerv Ment Dis. 1997;185(1):13-20.

16. Blanchard JJ, Brown SA, Horan WP, et al. Substance use disorders in schizophrenia: review, integration, and a proposed model. Clin Psychol Rev. 2000;20(2):207-34.

17.• Green AI, Zimmet SV, Strous RD, et al. Clozapine for comorbid substance use disorder and schizophrenia: do patients with schizophrenia have a reward-deficiency syndrome that can be ameliorated by clozapine? Harv Rev Psychiatry. 1999;6(6):28796. This paper describes the hypothesis that reward circuitry dysfunction may underlie the co-occurrence of schizophrenia and substance use disorders in patients with schizophrenia and how clozapine may ameliorate this dysfunction.

18.• Chambers RA, Krystal JH, Self DW. A neurobiological basis for substance abuse comorbidity in schizophrenia. Biol Psychiatry. 2001;50(2):71-83. These authors put forth an argument for the neurological basis of the co-occurrence of schizophrenia and substance use disorders.

19. Roth RM, Brunette MF, Green AI. Treatment of substance use disorders in schizophrenia: a unifying neurobiological mechanism? Curr Psychiatry Rep. 2005;7(4):283-91.

20. Drake RE, Mueser KT, Brunette MF, et al. A review of treatments for people with severe mental illnesses and co-occurring substance use disorders. Psychiatry Rehabil J. 2004;27(4):360-74.

21. Hunt GE, Siegfried N, Morley K, et al. Psychosocial interventions for people with both severe mental illness and substance misuse. Cochrane Database Syst Rev. 2013;10:CD001088.

22. Drake RE, O'Neal EL, Wallach MA. A systematic review of psychosocial research on psychosocial interventions for people with co-occurring severe mental and substance use disorders. J Subst Abuse Treat. 2008;34(1):123-38.

23. Bowers Jr MB, Mazure CM, Nelson JC, et al. Psychotogenic drug use and neuroleptic response. Schizophr Bull. 1990;16(1):81-5.

24. Wu BJ, Chen HK, Lee SM. Do atypical antipsychotics really enhance smoking reduction more than typical ones?: the effects of antipsychotics on smoking reduction in patients with schizophrenia. J Clin Psychopharmacol. 2013;33(3):319-28.

25. Voruganti LN, Heslegrave RJ, Awad AG. Neuroleptic dysphoria may be the missing link between schizophrenia and substance abuse. J Nerv Ment Dis. 1997;185(7):463-5.

26. McEvoy JP, Freudenreich O, Levin ED, et al. Haloperidol increases smoking in patients with schizophrenia. Psychopharmacology (Berl). 1995;119(1):124-6.

27. Samaha A. Can antipsychotic treatment contribute to drug addiction in schizophrenia? Prog Neuropsychopharmacol Biol Psychiatry. 2014;3(52):9-16.

28. Chau DT, Ahmed J, Wang TT, et al. Raclopride lessens the ability of clozapine to suppress alcohol drinking in Syrian golden hamsters. Neuropharmacology. 2011;61(4):646-52.

29. Young CR, Bowers Jr MB, Mazure CM. Management of the adverse effects of clozapine. Schizophr Bull. 1998;24(3):381-90.

30. Zimmet SV, Strous RD, Burgess ES, et al. Effects of clozapine on substance use in patients with schizophrenia and schizoaffective disorder: a retrospective survey. J Clin Psychopharmacol. 2000;20(1):94-8.

31. Green AI, Burgess ES, Dawson R, et al. Alcohol and cannabis use in schizophrenia: effects of clozapine vs. risperidone. Schizophr Res. 2003;60(1):81-5.

32. Drake RE, Xie H, McHugo GJ, et al. The effects of clozapine on alcohol and drug use disorders among patients with schizophrenia. Schizophr Bull. 2000;26(2):441-9. The first major demonstration of the effect of clozapine on alcohol drinking in patients with schizophrenia.

33. Brunette MF, Drake RE, Xie H, et al. Clozapine use and relapses of substance use disorder among patients with co-occurring schizophrenia and substance use disorders. Schizophr Bull. 2006;32(4):637-43.

34. McEvoy JP, Freudenreich O, Wilson WH. Smoking and therapeutic response to clozapine in patients with schizophrenia. Biol Psychiatry. 1999;46(1):125-9.

35. Brunette MF, Dawson R, O'Keefe C, et al. A Randomized Trial of Clozapine Versus Other Antipsychotics for Cannabis Use Disorder in Patients With Schizophrenia. J Dual Diagn. 2011;7 (1):50-63. 
36. Machielsen MW, Veltman DJ, van den Brink W, et al. The effect of clozapine and risperidone on attentional bias in patients with schizophrenia and a cannabis use disorder: An fMRI study. J Psychopharmacol. 2014;28(7):633-42. An important imaging study showing the effects of clozapine and risperidone on regional brain activity.

37. Smelson DA, Losonczy MF, Davis CW, et al. Risperidone decreases craving and relapses in individuals with schizophrenia and cocaine dependence. Can J Psychiatry. 2002;47(7): 671-5.

38. Machielsen M, Beduin AS, Dekker N, et al. Differences in craving for cannabis between schizophrenia patients using risperidone, olanzapine or clozapine. J Psychopharmacol. 2012;26(1):189-95.

39. van Nimwegen LJ, de Haan L, van Beveren NJ, et al. Effect of olanzapine and risperidone on subjective well-being and craving for cannabis in patients with schizophrenia or related disorders: a double-blind randomized controlled trial. Can J Psychiatry. 2008;53(6):400-5.

40. Sevy S, Robinson DG, Sunday S, et al. Olanzapine vs. risperidone in patients with first-episode schizophrenia and a lifetime history of cannabis use disorders: 16-week clinical and substance use outcomes. Psychiatry Res. 2011;188(3):310-4.

41. George TP, Ziedonis DM, Feingold A, et al. Nicotine transdermal patch and atypical antipsychotic medications for smoking cessation in schizophrenia. Am J Psychiatry. 2000;157(11):1835-42. An early study of atypical antipsychotics combined with nicotine replacement in the treatment of tobacco use disorder in patients with schizophrenia.

42. Llorca PM. Partial compliance in schizophrenia and the impact on patient outcomes. Psychiatry Res. 2008;161(2):235-47.

43. Rubio G, Martinez I, Ponce G, et al. Long-acting injectable risperidone compared with zuclopenthixol in the treatment of schizophrenia with substance abuse comorbidity. Can J Psychiatry. 2006;51(8):531-9.

44. - Green AI, Brunette MF, Dawson R, et al. Oral vs. Long-acting Injectable Risperidone in Schizophrenia and Co-Occurring Alcohol Use Disorder. J Clin Psychiat. In press. A study comparing oral and long acting injectable risperidone for the treatment of patients with dual diagnosis

45. Rosenheck RA, Krystal JH, Lew R, et al. Long-acting risperidone and oral antipsychotics in unstable schizophrenia. N Engl J Med. 2011;364(9):842-51.

46. Leatherman SM, Liang MH, Krystal JH, et al. Differences in treatment effect among clinical subgroups in a randomized clinical trial of long-acting injectable risperidone and oral antipsychotics in unstable chronic schizophrenia. J Nerv Ment Dis. 2014;202(1): 13-7.

47. Littrell KH, Petty RG, Hilligoss NM, et al. Olanzapine treatment for patients with schizophrenia and substance abuse. J Subst Abuse Treat. 2001;21(4):217-21.

48. Noordsy DL, O'Keefe C, Mueser KT, et al. Six-month outcomes for patients who switched to olanzapine treatment. Psychiatr Serv. 2001;52(4):501-7.

49. Petrakis IL, Leslie D, Finney JW, et al. Atypical antipsychotic medication and substance use-related outcomes in the treatment of schizophrenia. Am J Addict. 2006;15(1):44-9.

50. Sayers SL, Campbell EC, Kondrich J, et al. Cocaine abuse in schizophrenic patients treated with olanzapine versus haloperidol. J Nerv Ment Dis. 2005;193(6):379-86.

51. Smelson DA, Ziedonis D, Williams J, et al. The efficacy of olanzapine for decreasing cue-elicited craving in individuals with schizophrenia and cocaine dependence: a preliminary report. J Clin Psychopharmacol. 2006;26(1):9-12.

52. Litten RZ, Fertig JB, Falk DE, et al. A double-blind, placebocontrolled trial to assess the efficacy of quetiapine fumarate $\mathrm{XR}$ in very heavy-drinking alcohol-dependent patients. Alcohol Clin Exp Res. 2012;36(3):406-16.

53. Potvin S, Stip E, Lipp O, et al. Quetiapine in patients with comorbid schizophrenia-spectrum and substance use disorders: an open-label trial. Curr Med Res Opin. 2006;22(7):1277-85.

54. Brunette MF, Dawson R, O'Keefe C, et al. An open label study of quetiapine in patients with schizophrenia and alcohol disorders. Ment Health Subst Use. 2009;2(3):203-11.

55. Beresford TP, Clapp L, Martin B, et al. Aripiprazole in schizophrenia with cocaine dependence: a pilot study. J Clin Psychopharmacol. 2005;25(4):363-6.

56. Brown ES, Jeffress J, Liggin JD, et al. Switching outpatients with bipolar or schizoaffective disorders and substance abuse from their current antipsychotic to aripiprazole. J Clin Psychiatry. 2005;66(6):756-60.

57. Kim SH, Han DH, Joo SY, et al. The effect of dopamine partial agonists on the nicotine dependency in patients with schizophrenia. Hum Psychopharmacol. 2010;25(2):187-90.

58. Myrick H, Wright T. Clinical Management of Alcohol Abuse and Dependence, in The American Psychiatric Publishing Textbook of Substance Abuse Treatment. In: Galanter M, Kleber HD, editors. American Psychiatric Publishing Inc.: Arlington; 2008. p. 134

59. Mueser KT, Noordsy DL, Fox L, et al. Disulfiram treatment for alcoholism in severe mental illness. Am J Addict. 2003;12(3): 242-52.

59. Petrakis IL, Nich C, Ralevski E. Psychotic spectrum disorders and alcohol abuse: a review of pharmacotherapeutic strategies and a report on the effectiveness of naltrexone and disulfiram. Schizophr Bull. 2006;32(4):644-54. This paper discusses the use of the adjunctive treatments disulfiram and naltrexone in patients with co-occurring schizophrenia and alcohol use disorder.

61. Volpicelli JR, Watson NT, King AC, et al. Effect of naltrexone on alcohol "high" in alcoholics. Am J Psychiatry. 1995;152(4):613-5.

62. Adcock RA, Thangavel A, Whitfield-Gabrieli S, et al. Rewardmotivated learning: mesolimbic activation precedes memory formation. Neuron. 2006;50(3):507-17.

63. Rosner S, Hackl-Herrwerth A, Leucht S, et al. Opioid antagonists for alcohol dependence. Cochrane Database Syst Rev. 2010;(12): CD001867

64. Batki SL, Dimmock JA, Wade M, et al. Monitored Naltrexone without Counseling for Alcohol Abuse/Dependence in Schizophrenia-Spectrum Disorders. Am J Addict. 2007;16(4):253-9.

65. Petrakis IL, O'Malley S, Rounsaville B, et al. Naltrexone augmentation of neuroleptic treatment in alcohol abusing patients with schizophrenia. Psychopharmacology (Berl). 2004;172(3):291-7.

66. Garbutt JC, Kranzler HR, O'Malley SS, et al. Efficacy and tolerability of long-acting injectable naltrexone for alcohol dependence: a randomized controlled trial. JAMA. 2005;293(13): $1617-25$.

67. Naassila M, Hammoumi S, Legrand E, et al. Mechanism of action of acamprosate. Part I. Characterization of spermidine-sensitive acamprosate binding site in rat brain. Alcohol Clin Exp Res. 1998;22(4):802-9.

68. Littleton J, Zieglgansberger W. Pharmacological mechanisms of naltrexone and acamprosate in the prevention of relapse in alcohol dependence. Am J Addict. 2003;12 Suppl 1:S3-S11.

69. McGeehan AJ, Olive MF. The anti-relapse compound acamprosate inhibits the development of a conditioned place preference to ethanol and cocaine but not morphine. Br J Pharmacol. 2003;138(1):9-12.

70. Rösner S, Hackl-Herrwerth A, Leucht S, et al. Acamprosate for alcohol dependence. Cochrane Database Syst Rev. 2010;9: CD004332.

71. Ralevski E, O'Brien E, Jane JS, et al. Treatment With Acamprosate in Patients With Schizophrenia Spectrum Disorders and Comorbid Alcohol Dependence. J Dual Diagn. 2011;7(1-2):64-73. 
72. Ralevski E, O'Brien E, Jane JS, et al. Effects of acamprosate on cognition in a treatment study of patients with schizophrenia spectrum disorders and comorbid alcohol dependence. J Nerv Ment Dis. 2011;199(7):499-505.

73. Skradski S, White HS. Topiramate blocks kainate-evoked cobalt influx into cultured neurons. Epilepsia. 2000;41 Suppl 1:S45-7.

74. Johnson BA, Rosenthal N, Capece JA, et al. Topiramate for treating alcohol dependence: a randomized controlled trial. JAMA. 2007;298(14):1641-51.

75. Brady KT, Myrick H, Henderson S, et al. The use of divalproex in alcohol relapse prevention: a pilot study. Drug Alcohol Depend. 2002;67(3):323-30.

76. Salloum IM, Cornelius JR, Daley DC, et al. Efficacy of valproate maintenance in patients with bipolar disorder and alcoholism: a double-blind placebo-controlled study. Arch Gen Psychiatry. 2005;62(1):37-45.

77. Fertig JB, Ryan ML, Falk DE, et al. A double-blind, placebocontrolled trial assessing the efficacy of levetiracetam extendedrelease in very heavy drinking alcohol-dependent patients. Alcohol Clin Exp Res. 2012;36(8):1421-30.

78. Siris SG, Mason SE, Bermanzohn PC, et al. Adjunctive imipramine in substance-abusing dysphoric schizophrenic patients. Psychopharmacol Bull. 1993;29(1):127-33.

79. Ziedonis D, Richardson T, Lee E, et al. Adjunctive desipramine in the treatment of cocaine abusing schizophrenics. Psychopharmacol Bull. 1992;28(3):309-14.

80. Gulick D, Chau DT, Khokhar JY, et al. Desipramine enhances the ability of risperidone to decrease alcohol intake in the Syrian golden hamster. Psychiatry Res. 2014;218(3):329-34.

81. Kern AM, Akerman SC, Nordstrom BR. Opiate Dependence in Schizophrenia: Case Presentation and Literature Review. J Dual Diagn. 2014;10(1):52-7.

82. Unglaub W, Kandel M, Zenner D, et al. Neuroleptic Treatment of Opiate Addicts with a Comorbid Schizophrenia in a Methadone Maintenance Program. Psychiatr Prax. 2003;30(2): $121-4$.

83. Soyka M, Koller G, Schmidt P, et al. Cannabinoid receptor 1 blocker rimonabant (SR 141716) for treatment of alcohol dependence: results from a placebo-controlled, double-blind trial. J Clin Psychopharmacol. 2008;28(3):317-24.

84. Fischer AS, Whitfield-Gabrieli S, Roth RM, et al. Impaired Functional Connectivity of Brain Reward Circuitry in Patients with Schizophrenia and Cannabis Use Disorder: Effects of Cannabis and THC. Schizophr Res. 2014;158(1-3):176-82.

85. Ziedonis DM, George TP. Schizophrenia and nicotine use: report of a pilot smoking cessation program and review of neurobiological and clinical issues. Schizophr Bull. 1997;23(2):247-54.

86. Addington J, El-Guebaly N, Campbell W, et al. Smoking cessation treatment for patients with schizophrenia. Am J Psych. 1998;155(7):974-5.

87. Chou K-R, Chen R, Lee J-F, et al. The effectiveness of nicotinepatch therapy for smoking cessation in patients with schizophrenia. Int J Nurs Stud. 2004;41(3):321-30.

88. Baker A, Richmond R, Haile M, et al. A randomized controlled trial of a smoking cessation intervention among people with a psychotic disorder. Am J Psychiatry. 2006;163(11):1934-42.

89. Tidey JW, Rohsenow DJ, Kaplan GB, et al. Separate and combined effects of very low nicotine cigarettes and nicotine replacement in smokers with schizophrenia and controls. Nicotine Tob Res. 2013;15(1):121-9.

90. Caponnetto P, Auditore R, Russo C, et al. Impact of an electronic cigarette on smoking reduction and cessation in schizophrenic smokers: a prospective 12-month pilot study. Int J Environ Res Public Health. 2013;10(2):446-61.

91. Crunelle CL, Miller ML, Booji J, et al. The nicotinic acetylcholine partial agonist varenicline and the treatment of drug dependence: A review. Eur Neuropsychopharmacol. 2010;20(2):69-79.

92. Schoffelmeer AN, De Vries TJ, Wardeh G, et al. Psychostimulantinduced behavioral sensitization depends on nicotinic receptor activation. J Neurosci. 2002;22(8):3269-76.

93. Castle D, Baker AL, Richmond R, et al. Varenicline plus healthy lifestyle intervention for smoking cessation in psychotic disorders. Ann Clin Psychiatry. 2012;24(4):285-91.

94. Pachas GN, Cather C, Pratt SA, et al. Varenicline for Smoking Cessation in Schizophrenia: Safety and Effectiveness in a 12Week, Open-Label Trial. J Dual Diagn. 2012;8(2):117-25.

95. Dutra SJ, Stoeckel LE, Carlini SV, et al. Varenicline as a smoking cessation aid in schizophrenia: effects on smoking behavior and reward sensitivity. Psychopharmacology. 2012;219(1):25-34.

96. Williams JM, Anthenelli RM, Morris CD, et al. A randomized, double-blind, placebo-controlled study evaluating the safety and efficacy of varenicline for smoking cessation in patients with schizophrenia or schizoaffective disorder. J Clin Psychiatry. 2012;73(5):654-60.

96.• Evins AE, Cather C, Pratt SA, et al. Maintenance treatment with varenicline for smoking cessation in patients with schizophrenia and bipolar disorder: a randomized clinical trial. JAMA. 2014;311(2):145-54. This is an important trial demonstrating the efficacy and safety of verenicline for smoking cessation in patients with psychotic spectrum disorders.

98. Wing VC, Wass CE, Bacher I, et al. Varenicline modulates spatial working memory deficits in smokers with schizophrenia. Schizophr Res. 2013;149(1-3):190-1.

99. Liu M-E, Tsai S-J, Jeang S-Y, et al. Varenicline prevents affective and cognitive exacerbation during smoking abstinence in male patients with schizophrenia. Psych Res. 2011;190(1):79-84.

100. Smith RC, Lindenmayer JP, Davis JM, et al. Cognitive and antismoking effects of varenicline in patients with schizophrenia or schizoaffective disorder. Schizophr Res. 2009;110(1-3):149-55.

101. Hong LE, Schroeder M, Ross TJ, et al. Nicotine enhances but does not normalize visual sustained attention and the associated brain network in schizophrenia. Schizophr Bull. 2011;37(2):416-25.

102. Hong LE, Thaker GK, McMahon RP, et al. Effects of ModerateDose Treatment With Varenicline on Neurobiological and Cognitive Biomarkers in Smokers and Nonsmokers With Schizophrenia or Schizoaffective Disorder. Arch Gen Psychiatry. 2011;68(12):1195-206.

103. Litten RZ, Ryan ML, Fertig JB, et al. A double-blind, placebocontrolled trial assessing the efficacy of varenicline tartrate for alcohol dependence. J Addict Med. 2013;7(4):277-86.

104. Meszaros ZS, Abdul-Malak Y, Dimmock JA, et al. Varenicline treatment of concurrent alcohol and nicotine dependence in schizophrenia: a randomized, placebo-controlled pilot trial. J Clin Psychopharmacol. 2013;33(2):243-7.

105. Evins AE, Mays VK, Rigotti NA, et al. A pilot trial of bupropion added to cognitive behavioral therapy for smoking cessation in schizophrenia. Nicotine Tob Res. 2001;3(4):397-403.

106. Evins AE, Cather C, Rigotti NA, et al. Two-year follow-up of a smoking cessation trial in patients with schizophrenia: increased rates of smoking cessation and reduction. J Clin Psychiatry. 2004;65(3):307-11.

107. Evins AE, Cather C, Deckersbach T, et al. A double-blind placebocontrolled trial of bupropion sustained-release for smoking cessation in schizophrenia. J Clin Psychopharmacol. 2005;25(3):218-25.

108. George TP, Vessicchio JC, Termine A, et al. A placebo controlled trial of bupropion for smoking cessation in schizophrenia. Biol Psychiatry. 2002;52(1):53-61.

109. Cather C, Dyer MA, Burrell HA, et al. An Open Trial of Relapse Prevention Therapy for Smokers With Schizophrenia. J Dual Diagn. 2013;9(1):87-93. 
109. George TP, Vessicchio JC, Sacco KA, et al. A placebo-controlled trial of bupropion combined with nicotine patch for smoking cessation in schizophrenia. Biol Psychiatry. 2008;63(11):1092-6. This trial demonstrates the efficacy of bupropion combined with nicotine replacement as an adjunctive treatment for tobacco use disorder in patients with schizophrenia.

111. Wing VC, Barr MS, Wass CE, et al. Brain stimulation methods to treat tobacco addiction. Brain Stimul. 2013;6(3): $221-30$.
112. Barr MS, Farzan F, Wing VC, et al. Repetitive transcranial magnetic stimulation and drug addiction. Int Rev Psychiatry. 2011;23(5):454-66.

113. Prikryl R, Ustohal L, Kucerova HP, et al. Repetitive transcranial magnetic stimulation reduces cigarette consumption in schizophrenia patients. Prog Neuropsychopharmacol Biol Psychiatry. 2014;49:30-5.

114. Kuhn J, Buhrle CP, Lenartz D, et al. Deep brain stimulation in addiction due to psychoactive substance use. Handb Clin Neurol. 2013;116:259-69. 